\title{
PRESTRESSED MEMBERS UNDER NATURAL FIRES: A PRELIMINARY STUDY ON THE RESIDUAL BEHAVIOUR
}

\author{
NatasaKalaba $^{\mathrm{a}}$,Patrick Bamonte ${ }^{\mathrm{a}}$, Roberto Felicetti ${ }^{\mathrm{a}}$ \\ ${ }^{\mathrm{a}}$ Politecnico di Milano, Department of Civil and Environmental Engineering, Milano, Italy
}

\begin{abstract}
The present work is aimed at investigating the residual behaviour of prestressed concrete members exposed to natural fires, since experience has shown that substantial losses of the load bearing capacity may take place during the cooling phase. This topic is of great practical significance, because the knowledge of the residual response can help the engineers to decide whether a structure can be refurbished after being exposed to fire, with minor costs, or whether demolition is inevitable.Sequentially coupled thermo-mechanical analysis was performed on typical inverted $\mathrm{T}$ and double T-beam sections, subjected to heating and subsequent cooling. The results show that the residual deflection is primarily governed by the load level and the section shape and that the magnitude of the residual deflection can be even several times higher than the initial value.
\end{abstract}

Keywords:prestressed concrete, natural fire, residual behaviour, cooling

\section{INTRODUCTION}

Prestressed elements are a very popular and advantageous structural solution for many reasons, such as the higher speed of the construction process and the possibility of larger span-to-depth ratios. Their particular sensitivity to high temperatures, thatcomes from the use of cold worked steel and thin sections where the prestressingsteel is poorly protected, imposes the need for further and broader research on their behaviour and particularly under natural fires. Modelling the cooling phase certainly brings up many difficulties, but it also covers a wider range of situations of practical interest, in comparisonto the case of standard fires, that feature only the heating phase.As a matter of fact, besides allowing to investigate the possibility of failure during the cooling phase, it gives the opportunity to study the residual behaviour. This is very significant in view of the structural post-fire assessment,since itcan help answeringa crucial question: is a structure that survived a fire safe or not?Should it be repaired or demolition is inevitable? Given the thermal properties of concrete and its high insulating power, failure is generally not a big concern, except for thin and sizably loaded sections, or whenever $2^{\text {nd }}$-order effects play a significant role. In the case of fires of short duration, as it is very often the case in reality, a concrete member is not expected to fail; the level of damage suffered and the possible consequences as far as the residual bearing capacity is concerned, however,arecertainly topics that deserve to be investigated in depth.

Up to this date, few studies were focused on the residual behaviour of P/C structural elements, as the cooling phase is often neglected in the existing numerical and experimental studies.Moreover there is also an obvious lack of data on the residual materials' properties (especially for prestressing steel), which are certainly different from the so called "hot" properties. Among the existing studies on the structural post-fire assessment of P/C members, worth highlighting is the one conducted by Taerwe et al. (2006), who performed full scale tests on a several components of a building composed of precast elements. The structural behaviour of the whole building was judged as satisfactory, as no major collapse took place. Moreover, considering the mutual connections between the different members yielded more favourable results than when the single elements wereseparately tested in the laboratory. Severely damaged elements were repaired and then submitted to a static loading test, where it was demonstrated that concrete members can be reused 
after fire, if appropriate repair techniquesare applied. Another research worth mentioning is reported in the paper by Whelan et al. (2014), where the focus was on various non-destructive testing techniques applied to the fire-damaged double-tee joists of a precast, prestressed roof system. The test results were compared with empirical models of residual compressive strength and residual elastic modulus of concrete, and they were in a good agreement. Particular focus was put on camber surveying, which, if performed withsufficient accuracy, may provide useful evidence of variations of the integrity of the concrete, and of potential prestress loss.

\section{NUMERICAL ANALYSIS}

Two typical P/C beam sections were selected for a numerical investigation (Figure 1). The chosen sections are rather typical within the field of prestressed members.Moreover, they are expected to highlight rather different structural behaviours, sincethe double T-beam is rather slender, with a thin concrete cover to prestressing steel bars, while the inverted T-beam is massive and the steel is well protected by the concrete.For both sections, reference mechanical properties were assumed at ambient temperature (concrete: $\mathrm{f}_{\mathrm{c}}=40 \mathrm{MPa}$; reinforcing steel: $\mathrm{E}_{\mathrm{s}}=210 \mathrm{GPa}, \mathrm{f}_{\mathrm{sy}}=500 \mathrm{MPa}$; prestressing steel: $\mathrm{E}_{\mathrm{p}}=195 \mathrm{GPa}, \mathrm{f}_{\mathrm{py}}=1860 \mathrm{MPa}$; prestressing at the onset of fire $=1000 \mathrm{MPa}$ ).

Sequentially coupled thermo-mechanical analyses were performed on the two sections, with the aim of obtaining deformation at the reference point and curvature of the section. However, in view of the assessment of $\mathrm{P} / \mathrm{C}$ members in residual conditions, rather than on sectional deformation, the focus is on the deflections. Obtainingthe moment-curvature relationship for a sufficient number of points along the beam length enables afterwards to compute the mid-span deflection.

As an input fire scenario, ISO834 fire was used, with a linear cooling branch (Figure 2). Moreover, fire scenario was extended in time, allowing the strands to cool down to ambient temperature. The duration of the heating phase for thedouble T-beam was set to 15 minutes, with an overall fire duration of 285 minutes.For the Inverted T-beam,the fire duration was set to 60 minutes, with an overall fire duration of 675 minutes. The cooling rate for both fire scenarios wasset to $5^{\circ} \mathrm{C} / \mathrm{min}$.

\subsection{Constitutive model - Concrete}

The adopted constitutive model for concrete is based on the implicit EN 1992-1-2 model. Including a cooling branch in the temperature-time curve, however, implies that the constitutive model should be properly adapted, to allow for possible unloading. The slope of the unloading branch canbe defined on the basis of the residual elastic modulus.In this way, the lower deformability in unloading due to the irreversible nature of the load-induced thermal strain is taken into account.

As a consequence, the residual elastic modulus can be expressed as:

$$
E_{r}=k E_{n o}
$$

where $E_{n o}$ is the modulus of elasticity in hot conditions, and $k$ is a constant value that can be suitably calibrated on the basis of available experimental results; in the numerical analyses presented in the following, $k=1.25$.

As can be seen in Figure 3, once the stress corresponding to the peak strain is attained, only plastic loading (strain increase) or unloading on a linear branch (strain decrease) can occur. It is worth noting that the stress can go to zero for a value of strain (i.e. cracking strain) larger than zero. Below this value of strain, as it is usually done in the numerical analysis of concrete members, the tensile stresses in the concrete are neglected.

The cracking strain can be computed as follows:

$$
\varepsilon_{C, i+1}=\varepsilon_{p} \quad-\sigma_{L, l+1}\left(\varepsilon_{m} n, l\right) / E_{r}
$$

As for the thermal damage, in the heating phase the stress-strain curves are adapted to allow for the decreasing value of the compressive strength, and the increasing deformability. In the cooling 
phase, since the thermal damage is usually considered as a function of the maximum temperature only (i.e. fully irreversible), the stress-strain curves are not updated.

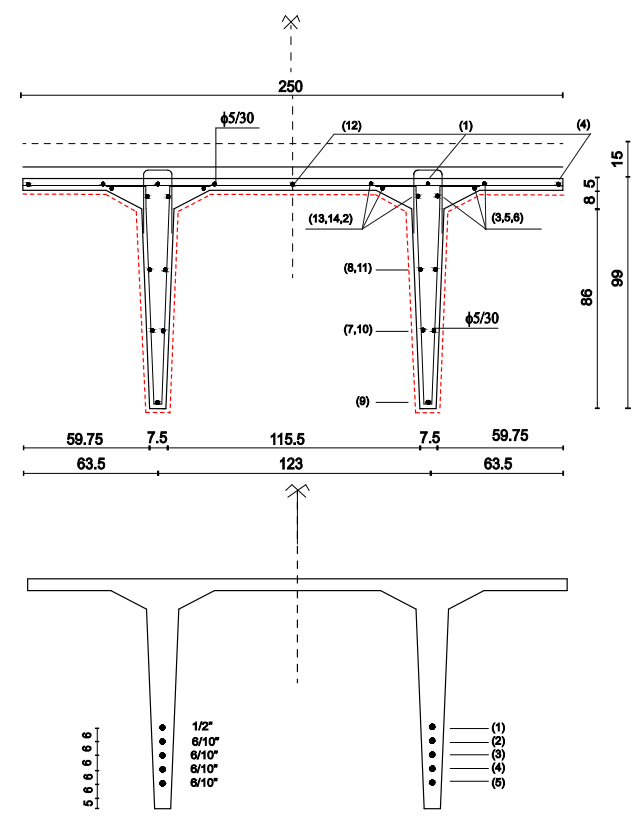

(a)
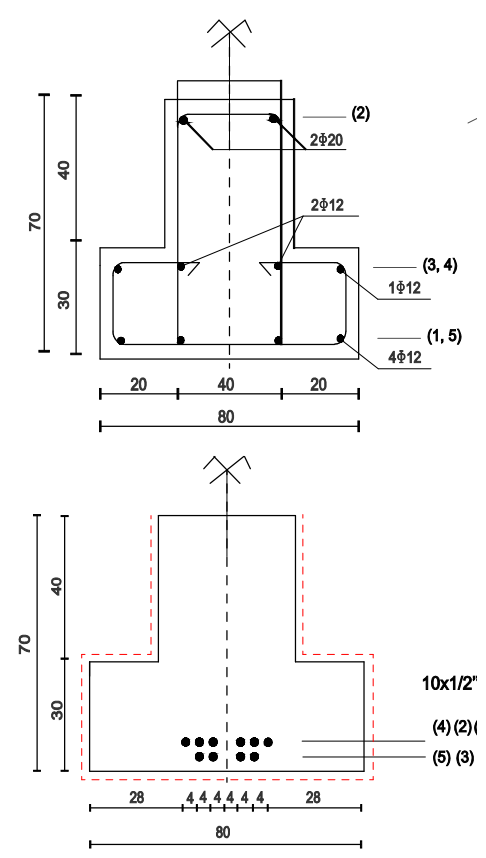

(b)

Fig. 1 Prestressed concrete sections considered in the numerical analyses: (a) double-tee section; and (b) inverted T-beam section

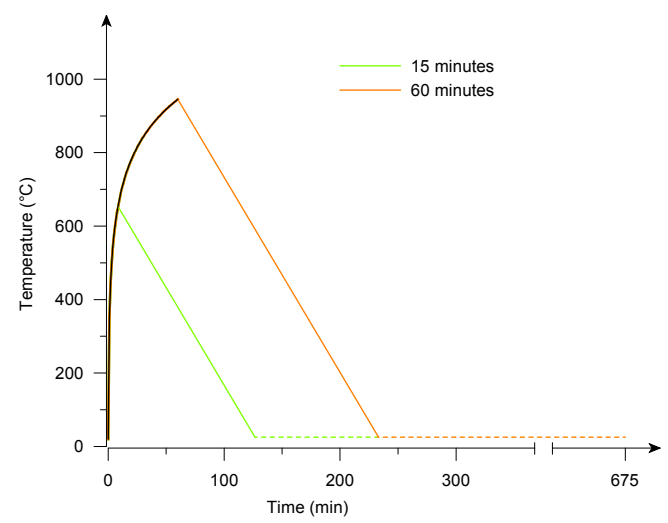

Fig. 2 Fire scenario: variation of the fire duration, at constant cooling rate

\subsection{Constitutive model - Steel}

Elastic perfectly-plastic stress-strain laws for both prestressing and reinforcing steel have been adopted, on the basis of the provisions contained in EN1992-1-2.

As in the case of concrete, two main factors governing the stress-strain behaviour of steel are the maximum temperature experienced and the load path. The accumulation of residual plastic deformation changes the position, but not the shape of the stress-strain diagram. 

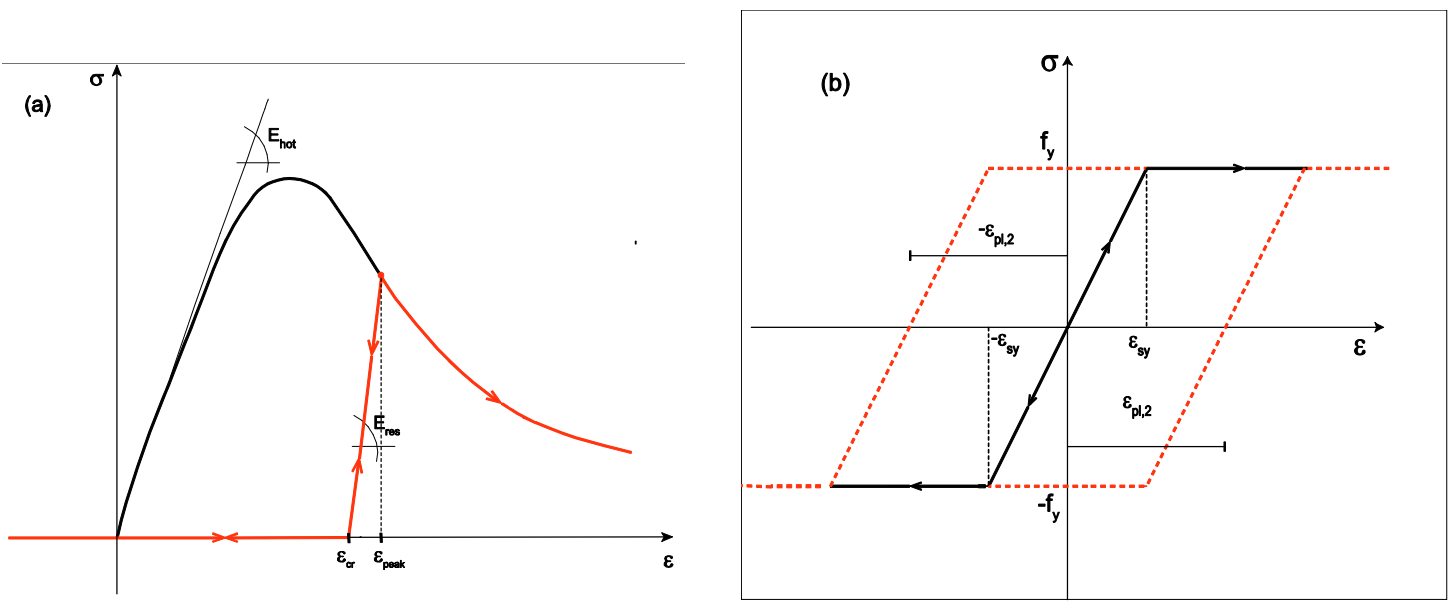

Fig. 3 Stress-strain model for (a) concrete in compression and (b) steel at a given temperature, in loading and unloading

\subsection{Thermal strain - Concrete}

The evolution of the thermal dilation with temperature was computed according to the provisions of EN1992-1-2 (concrete with siliceous aggregate). It is well known that the thermal incompatibility between cement paste and aggregate during heatingcauses a system of cracks to develop in the concrete, and that these cracks do not completely close during cooling. Therefore, a certain amount of residual thermal deformation should be accounted for, which primarily depends on the aggregate type and maximum temperature experienced. Based on a rather limited number of experimental results (RILEM, 1985), the residual thermal strain for a maximum temperature $T_{m}>500^{\circ} \mathrm{Cis}$ assumed to be equal to $50 \%$ of the maximum thermal dilation experienced, with the thermal strain recovery upon cooling being a linear function of temperature.For maximum temperatures $T_{m}<$ $500^{\circ} \mathrm{C}$ the residual thermal deformation is considered negligible.

\subsection{Thermal strain - Steel}

The thermal strain for both prestressing and reinforcing steel is computed according to the expressions provided by EN 1992-1-2. No residual thermal strain has been assumed for steel, which is considered ableto fully recoverthe initial geometry upon cooling. This assumption is in agreement with the rather limited number of experimental results available to this date (e.g. Elghazouli et al. 2009, Mohamed and Salah, 2012).

\section{RESULTS}

As expected, for the lower load level, camber (upward deflection) dominates the response, given that the temperatures are rather low; as a consequence, significant loss of strength and stiffness in the prestressing steel does not take place. As the temperature increases, the role of the prestressingsteel becomes less significant, as the prestressing losstakes on.Moreover, the deformability of concrete markedly increases, and the applied load tends to bend the beam downwards. Concrete is a material of high insulating power: consequently, the temperature in the strands keeps increasing some time after the onset of ambient cooling. The time of attainment of the maximum temperature in the strands depends mainly on the concrete cover and on the massivity of the section. Therefore, for a double T-beam section, the maximum averagetemperature in the strands is $430^{\circ} \mathrm{C}$ and it is reached after 90 minutes of fire, while for the more massive inverted Tbeam section, the maximum temperature $\left(314^{\circ} \mathrm{C}\right)$ is reached after 165 minutes from the beginning of the fire. During the cooling of the strands, the deflection trend reverses, leading eventually to residual downward deflection for the higher load level and residual upward deflection for the lower 
load level (note that the vertical line on the plot stands for the start of the cooling of the strands). To get a clear picture, it is useful to compare the residual deflection with the initial one. It can be seen from the results (Figure 4) that in the case of a double T-beam, for the lower load level, residual camber is two times higher than the initial one, while for the higher load level, residual downward deflection is around 10 times higher than the initial one. On the other hand, for the double T-beam for the lower load level, residual deflection is around 2 times higher than the initial value, while for the higher load level, residual downward deflection is around 5 times higher than the value of the initial camber (note that positive sign represents downward deflection).

It is well known that during first heating, concrete in compression exhibits an irrecoverable component of strain, called transient creep strain. Transient creep is considered either in implicit (widely used Eurocode model) or explicit manner. Among the various available explicit constitutive models developed by different Authors, neither one of them established itself as a far superior than the others. In this work, the most recent model, which also accounts for all the possible stresstemperature combinations and developed by Gernay and Franssen (2014), was used for the purpose of the validation of the obtained results.
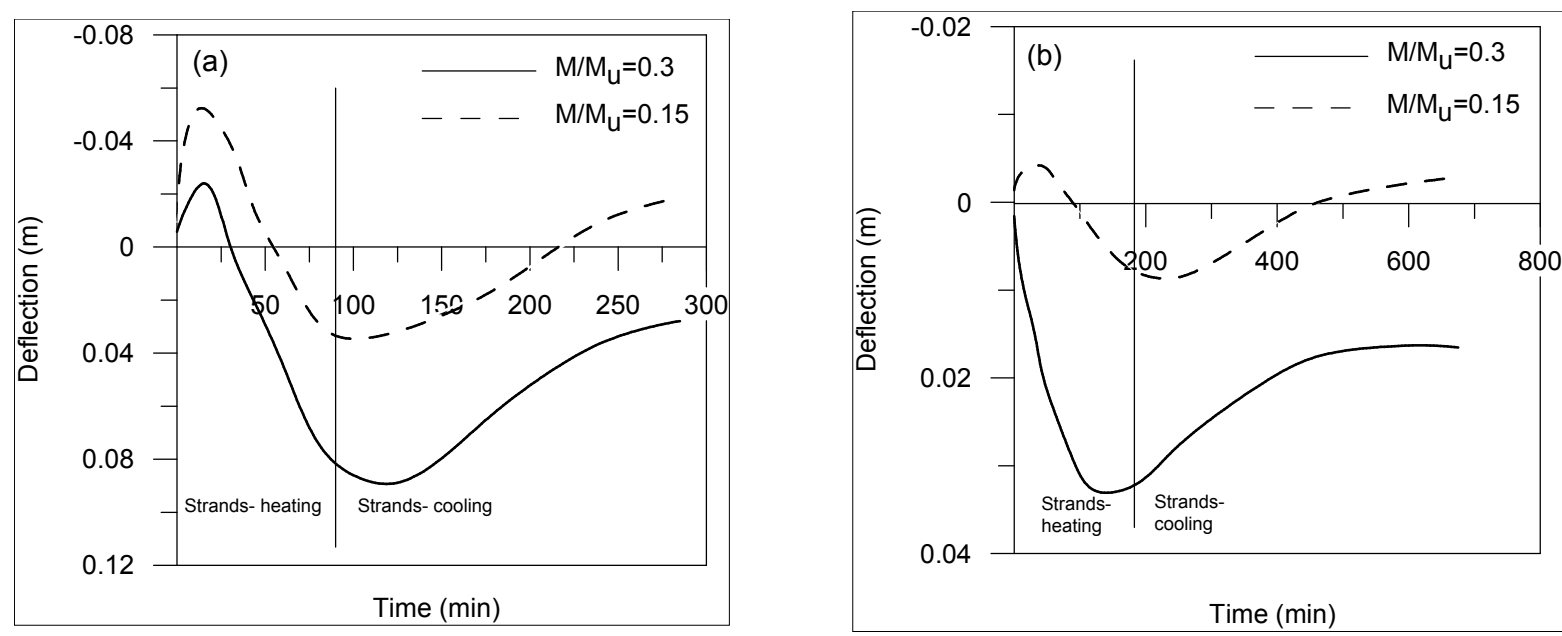

Fig. 4In time evolution of the midspan deflection for: (a) Double T-beam (heating phase duration of 15 minutes) and (b) Inverted T-beam (heating phase duration of 30 minutes); for different load levels
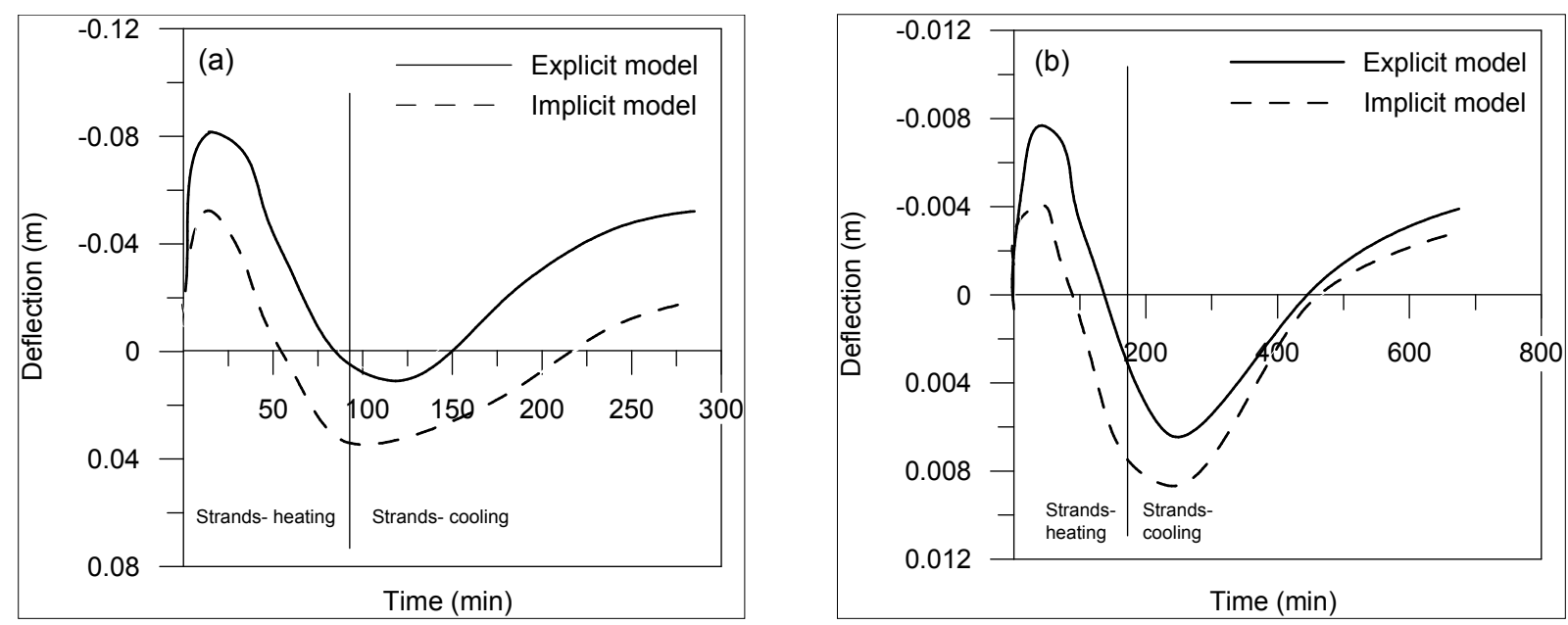

Fig. 5In time evolution of the midspan deflection for: (a) Double T-beam (heating phase duration of 15 minutes) and (b) Inverted T-beam (heating phase duration of 30 minutes); using implicit and explicit constitutive model for concrete 
The comparison between in time evolution of deflection with implicit and explicit model was done for both sections, and for a load level $\mathrm{M} / \mathrm{M}_{\mathrm{u}}=0.15$ (Fig. 5). The agreement between the two models for an inverted T-beam is definitely good: slight differences are visible in the cooling phase, where unloading is likely to occur, however the difference in the residual deflection is slightly underestimated with the implicit model. As for the Double T-beam section, difference is more pronounced.

\section{CONCLUSIONS}

From the obtained results it can be concluded:

- evolution of the deflection in the beam midspan is primarily governed by the temperature in the strands and load level;

- downward residual deflection can be expected for the higher load levels and when the significant loss of stiffness in the strands took place, due to increase in temperature;

- even for the short fire duration, due to the insulating properties of concrete, strands experience delayed cooling, which is particularly significant for the residual behaviour. Upon cooling of the strands, trend in the deflection changes, leading to decrease in sag and increase in hog;

- residual deflections can be multiple times greater than the initial values, especially for higher load levels.

\section{REFERENCES}

Elghazouli A.Y., Cashell K.A., Izzuddin B.A. 2009. Experimental Evaluation of the Mechanical Properties of Steel Reinforcement at Elevated Temperature. Fire Safety Journal, 44, pp. 909-919.

Eurocode 2 - EN 1992-1-2: Design of Structures, Part 1-2: General Rules- Structural Fire Design, 2004, European Committee for Standardization, Brussels, Belgium.

Eurocode 4 - EN 1994-1-2: Design of Composite Steel and Concrete Structures. Part 1-2: General RulesStructural Fire Design, 2005, European Committee for Standardization, Brussels, Belgium.

Gernay T., Franssen J.M. 2012. A Formulation of the Eurocode 2 Concrete Model at Elevated Temperature That Includes an Explicit Term for Transient Creep. Fire Safety Journal, 51, pp. 1-9.

Mohamed G., Salah M.D. 2012. Analysis of Collapse for Concrete Columns During and After the Cooling Phase of a Fire". XXX Recontres AUGC-IBPSA, 6-8 June 2012, Chambery, Savoie

RILEM (1985) Properties of Materials at High Temperatures: Concrete. Ed. by U. Schneider, publ. by the Department of Civil Engineering, University of Kassel (Kassel, Germany), 131 pp.

Taerwe L., Poppe A.-M., Annerel E. 2006. Structural Assessment of a Pretensioned Concrete Girder after Fire Exposure, in 2nd International fib Congress, 5-8 June 2006, Naples, Italy, 12 pp.

Whelan M., Tempest B., Scott D. 2014. Post-Fire Nondestructive Evaluation of a Prestressed Concrete Double-Tee Joist Roof. Journal of Performance of Constructed Facilities, 29(2), 04014055. 